\title{
Forecast Mekong
}

Forecast Mekong is part of the U.S. Department of State's Lower Mekong Initiative, which was launched in 2009 by Secretary Hillary Clinton and the Foreign Ministers of Cambodia, Laos, Thailand, and Vietnam to enhance partnerships between the U.S. and the Lower Mekong River countries in the areas of environment, health, education, and infrastructure. The U.S. Geological Survey (USGS) is working in close cooperation with the U.S. Department of State to use research and data from the Lower Mekong Basin to provide hands-on results that will help decision makers in Lower Mekong River countries in the planning and design for restoration, conservation, and management efforts in the basin.

Forecast Mekong provides a forum for regional partners, scientists, and engineers in the Lower Mekong Basin to share data and support local research efforts and elevate knowledge about the vital importance of the Mekong River and Delta in maintaining food security and livelihoods in the region. Ultimately, Forecast Mekong will lead to more informed decisions about how to make the Lower Mekong Basin resilient and sustainable in the face of climate change, population growth, economic stresses, and other impacts.

Initial efforts of Forecast Mekong in 2009 highlighted the increasing cooperation between the U.S. and Lower Mekong River countries in the areas of environment and food security. An offshoot of the Delta Research and Global Observation Network (DRAGON) Partnership, Forecast Mekong was conceived as a platform for data integration, modeling, and visualization systems to help policy makers and the public understand and predict outcomes of water-management projects and climate variability in the Lower Mekong Basin. The USGS, in partnership with the Lower Mekong River governments and universities, is working to provide valuable planning tools to visualize and predict the consequences of climate change, water-resources development, and river management.

In 2011 Forecast Mekong is undertaking a variety of activities to help inform managers, to help build science capacity of institutions in the Lower Mekong Basin, and to support local research efforts.

\section{Data Visualization}

The USGS is building a graphic visualization tool (GVT) that will assist the Lower Mekong River countries in understanding the benefits and consequences of water-resources development projects such as a hydropower dams. The GVT will focus on an existing hydropower dam on a tributary of the Mekong River and will demonstrate the utility of using visualization tools at proposed dam sites on the main stem of the Mekong River to better understand the potential effects of hydropower and irrigation dams on the hydrology and ecology of the Mekong River and Delta. The GVT is designed to clearly illustrate the results of Mekong River Commission (MRC) hydrologic model predictions of river flow, water quality, and salinity conditions for different regional development scenarios including proposed dams. Along with the MRC, the USGS is sharing information with other organizations working on related issues, such as the Natural Heritage Institute and the International Crane Foundation.

This project includes the following tasks:

- construct a computer animation for a tributary of the Mekong River that is based on a digital elevation model and associated hydrologic, political, and ecological boundaries and layers from USGS datasets.

- produce a temporal simulation of effects of altered hydrology and associated effects of disrupted fish migration, change in fisheries biodiversity and productivity, rice cultivation area, and crop production after dams are constructed.

- provide all the visualization and hydrologic models with annotation to show proof of concept and to stimulate data and idea exchange and the production of peer-reviewed, scientifically defensible products.

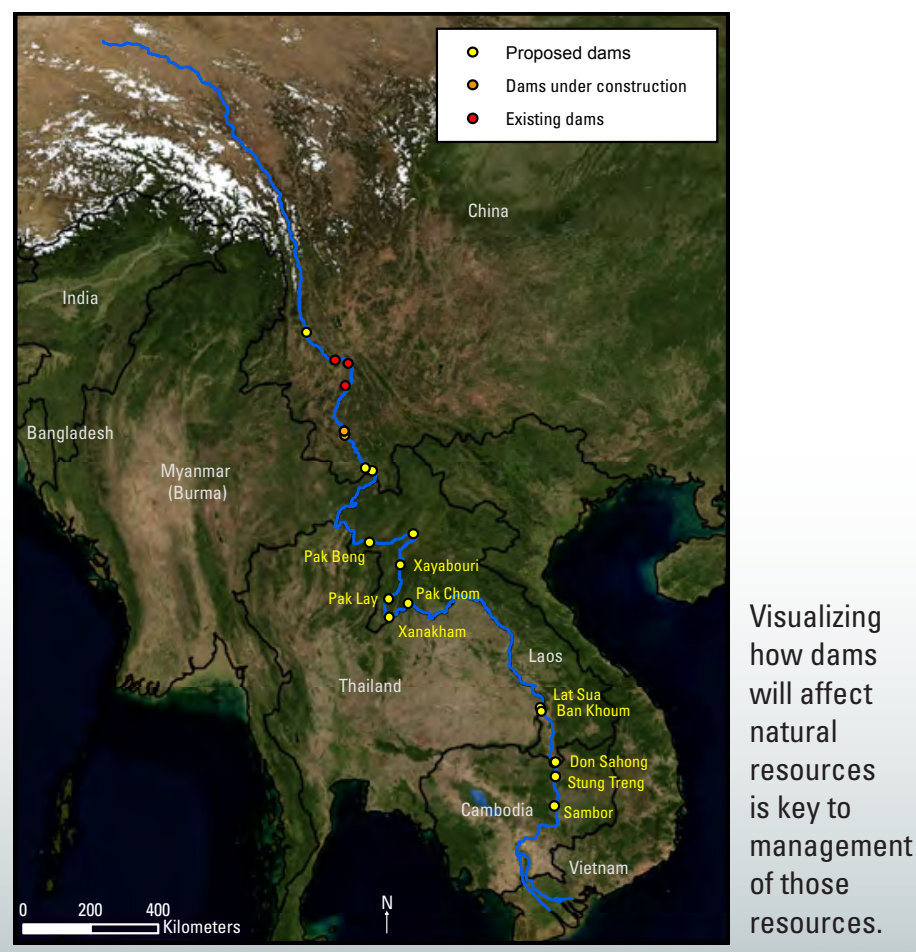




\section{Scientific Capacity Building}

The USGS is engaging regional partners in the Lower Mekong Basin to support the development of local scientific capacity and research efforts by providing the following:

- technical support for a study of Persistent Organic Pollutants (POPs) led by scientists from the International Crane Foundation, the University of Science in Ho Chi Minh City, Can Tho University, and others in the Mekong Wetlands University Network. As part of a workshop in December 2010 at the Vietnam University of Science, USGS assisted with the development of field sampling protocols, provided training in wetland mapping and sediment sampling techniques, and provided Landsat imagery to help identify sampling locations.

- a USGS senior-level groundwater hydrogeologist for a 90-day assignment to the MRC office in Phnom Penh, Cambodia, beginning in April 2011. The hydrogeologist will advise the MRC on a variety of groundwater issues such as transboundary groundwater movement and usage in the Lower Mekong Basin and the development of a groundwater management plan.

- two USGS geospatial scientists to the DRAGON Institute at Can Tho University in Vietnam for a 45-day assignment in the summer and fall of 2011. These scientists will be focused on providing training and technical assistance to university students and researchers on spatial database development, Web-based mapping applications, and data integration.

- a hydrologist to teach a course in Thailand on sediment transport for the MRC in the spring of 2011.

- remote sensing experts to teach a radar-based mapping workshop requested by Can Tho University.

- assistance with the development and funding of small projects at Can Tho University related to fisheries research, community-based water-quality monitoring, and remote sensing.

Other recent related activities included providing geographic information system (GIS) and remote sensing training in 2010 at the annual Mekong Wetlands University Network training course, organizing and sponsoring a special session on the Mekong River at the Deltas in Times of Climate Change conference in the Netherlands, and facilitating the signing of a Memorandum of Understanding between the U.S. Department of the Interior and the Vietnam Ministry of Natural Resources and Environment.

\section{Knowledge Transfer}

The United States has a long history of water-resources development and the effects of multipurpose dams on large river systems such as the Mississippi are well documented. The dams in the Mississippi River Basin provide benefits including hydropower, navigation, flood control, and irrigation, but they also have consequences including alteration of the ecosystem and the hydrologic process and threatening and endangering aquatic and terrestrial species. The USGS will research and then synthesize historical and current documents and datasets for the purpose of describing and quantifying changes in flow, water quality, ecology, geomorphology and sediment in the Mississippi River Basin, including the Mississippi River Delta. The synthesis document will be published as a USGS report, thereby providing wide distribution of the document and its findings. The report will serve as a primer in water-resources development for a large river basin and provide lessons learned from decades of river management. This information can be used to compare restoration, conservation, and management efforts in the Mississippi River Basin with proposed waterresources development including hydropower dams in other major river systems such as the Mekong.

\section{Data Sharing}

The new Forecast Mekong Web site (http://deltas.usgs.gov/ $\mathrm{fm} /$ ) provides a publicly available Web interface to serve data, reports, and scientific visualization products.

- The Web site includes an interactive Web mapping application to view and download regional downscaled climate data for the Lower Mekong Basin to aid in climate change research in Southeast Asia.

- Monthly cloud-filtered and monthly-averaged Moderate Resolution Imaging Spectroradiometer (MODIS) satellite images are also included in the Web mapping application to provide a bird's eye view of the Lower Mekong Basin.

- The MODIS images were used to develop baselines of conditions for the widely used Normalized Difference Vegetation Index (NDVI). Departures from baseline conditions were calculated each month from 2002 to 2010 and can be used to monitor changes in growth patterns of plants and flooding or drought extent. USGS scientists are automating the image acquisition and processing so that new monthly NDVI data will be continually available on the Forecast Mekong Web site.

\section{By D. Phil Turnipseed}

\section{For more information, contact}

Director

U.S. Geological Survey

National Wetlands Research Center

700 Cajundome Blvd.

Lafayette, LA 70506

337-266-8500

nwrcdirector@usgs.gov

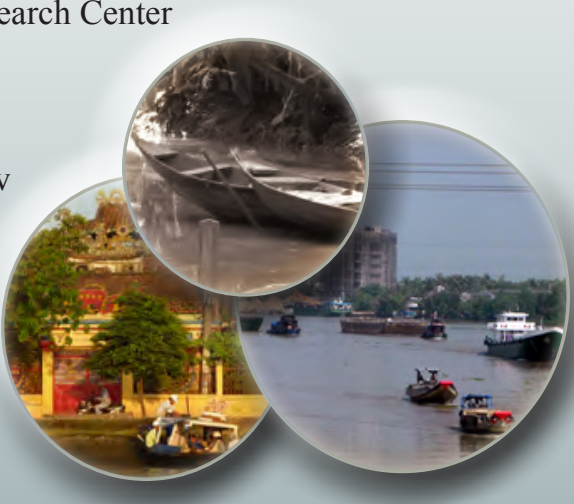

